\title{
Innovative methods reformation for professional English teaching in environmental science and engineering major
}

\author{
Mingliang Zhang ${ }^{a}$, Haixia Wang ${ }^{b}$ \\ School of resources and environment, University of Jinan, Jinan 250022, China; \\ astu_zhang@ujn.edu.cn, bstu_wanghx@ujn.edu.cn
}

Keywords: teaching method, reformation, professional English.

\begin{abstract}
The existing problems in professional English teaching for environmental science and engineering major were analyzed and summarized according to the investigation of the present teaching methods and situations. In order to cultivate students' innovation and practice ability and improve the teaching quality, a series of new teaching method were explored and put forward in professional English teaching, such as focusing on the innovation of curriculum content, mobilizing the enthusiasm of students through the special report and the special subject study, stimulating students' interest in learning through teaching the latest case or hot issues related with major, varying teaching approaches and assessment methods, encouraging and organizing students to participate in classroom interaction, strengthening the students' oral and writing training. Through the innovative practice of the above teaching methods, it showed that the teaching quality and performance has been effectively improved so that students' reading and writing ability in English literature can be enhanced. It is also helpful to students to carry out scientific and technological communication with foreigners by using specialist English.
\end{abstract}

\section{Introduction}

Professional English is a compulsory course for environmental science and Engineering major in colleges in China. It is an important part of environmental science and engineering curriculum system. The purpose of professional English teaching is to enable students to master professional vocabulary for environmental science and engineering, to read and understand professional English literature, to have ability of professional English writing, translation and communication so that it can lay a good foundation for environmental science research in the future.

With the increasing international academic exchanges, the ability of English reading and writing and academic communication has become one of the important skills of scientific researchers to participate in international academic exchanges. It is necessary to master professional English for students with environmental science and engineering majors. However, there are still many problems in bilingual teaching, such as the concept of bilingual teaching and the task is not clear, the shortage of teachers with bilingual teaching ability, traditional teaching methods, and relatively poor of students' professional English. At present, these factors mentioned have seriously restricted the improvement of teaching quality. Thus, it is urgent task for professional English teachers how to reform the teaching method and improve the teaching quality so that the students can master the course content in a limited time.

\section{The main problems existing in specialist English teaching}

\subsection{Out-dated teaching contents}

A suitable textbook is basic to the teaching performance and effect of the course. At present, English teaching textbook is mainly based on the knowledge structure and language ability of English. In the bilingual teaching, the choice of the textbooks is mainly divided into two categories, one kind is domestic textbooks, and another one is the original edition textbook (written by foreigner). Domestic textbooks are widely used in many colleges, while few original edition textbook is available. 


\subsection{Purpose of teaching}

At present, professional English course for environmental science and engineering major in mostly domestic colleges is $24-32$ hours learning course. It is very unrealistic in this short period of time to master professional English listening, speaking, reading and writing. Therefore, it is very important to clearly define the teaching objective.

\subsection{Traditional teaching method}

Most teachers use a simple "translation method" to teach professional English courses. The traditional cramming (force-feeding) method of teaching is still prevalent and predominant, ignoring the active learning ability of students. For the traditional teaching mode, teachers lead students to sentence translation and memorizing new words and phrases. The entire teaching processes focus on the teacher's role and action, and pay the less attention to students in the classroom. The traditional teaching mode is relatively inflexible lack of interest and subjective initiative in learning.

\subsection{Examination}

Examination is often the most concern of the students, and the assessment methods have played a guiding role for the students' study and ability. At present the assessment of professional English mainly depends on the final exam (accounted for absolute weight). Although this way can play a certain role in strengthening the knowledge, more students focus on mechanical memorization and vocabulary sentence translation. The examination method does not fully examine the ability of flexible use of professional knowledge in listening, speaking, reading and writing.

\section{The main reform measure in professional English teaching}

\subsection{Suitable textbooks and diverse teaching materials}

Selection of suitable textbook for professional English teaching is very important to achieve good teaching quality. It is a short time of 24-32 hours learning for professional English teaching, and it is impossible for students to master the entire knowledge of professional English. If possible, the course time should be lengthened. At present, the textbooks are mainly divided into two categories, one kind is domestic textbooks, and another one is the original edition textbook. Domestic textbooks are widely used in many colleges, while few original edition textbook is available. We have made questionnaire investigation about the selection of textbook. The survey results also show that most of students believe original English language as teaching materials, and about half of students dislike the domestic textbook, and ask the teacher to add the latest professional knowledge and news through China daily, CNN and other channels. Select the appropriate materials related to environmental science and engineering by downloading the recently published literature, accessing latest network information or the technology frontier. It can attract students' interest in learning. The hot issues in recent year, smog, air pollution, $\mathrm{PM}_{2.5}$, biodiversity, wetland protection can be used as course materials.

\subsection{Emphasis on interaction and participation in classroom}

In the teaching process in classroom, the teacher should change the traditional teaching mode of the students' passive learning, and encourage students to actively participate in the teaching process in a variety of ways. As for specific hot issue, students can freely form several study groups (cooperative learning) to discuss actively and finally make a short lecture in the classroom. The practice shows that this method increases the students' initiative participation, stimulates the students' enthusiasm for learning, and improves the students' enthusiasm in the classroom teaching, and also improves the students' ability of expression.

In order to encourage the student's participation in classroom, the author breaks the tradition of teachers' teaching and students' passive learning. Taking students as the main body in teaching, the students themselves choose and professional related English literature, to read and translate the literature within one or two week's time, finally in the form of meeting report to introduce the contents of the literature. The teacher as minor role explains and comments the performance of students. For example, we have organized the discussion on the hot issue in recent year smog in China. In the classroom, students discuss the definition of smog, the cause of smog, the danger of smog, how 
to decrease the smog and how to deal with smog for us. Students would like to collect the data and information on smog, and they include that direct emissions, as well as physical and chemical reactions of the emissions in the air together, have triggered the smog. Emissions from the manufacturing sector and coal-burning processes contributed half of the direct emissions. Students have high enthusiasm to participate because smog is so close to them and affect them directly.

\subsection{To cultivate students' scientific writing skills}

It is very important to clearly define the teaching objective. The purpose of professional English teaching is to enable students to master professional vocabulary for environmental science and engineering, to read and understand professional English literature, to have ability of professional English writing, translation and academic communication. According to investigation and analysis, the students' writing and speaking ability was poorer than reading ability. One important task to learn professional English is to provide the foundation for academic communication and scientific paper writing. Thus, the cultivation of students' writing skill and speaking ability is one important objective in professional English teaching process.

\subsection{Diverse teaching methods}

In the teaching method, multimedia teaching was widely used (including Microsoft PowerPoint , slides, vivid pictures, animation, film clips and other video data related to environmental science and technology, etc.) to increase the amount of information and simulate the students' interests in learning. In recent years, the film and related video data (air pollution and control, wastewater treatment, solid waste landfill, ecological restoration) related to environmental problems are increasing, which can be used as the multimedia data in the teaching of professional English. The teaching practice shows that in the course of teaching, playing several relevant video films can significantly mobilize the enthusiasm of learning, and to some extent reduce the boring of professional English.

The use of heuristic teaching should be encouraged in the classroom, the use of existing expertise as the basis for the proposed problem, the flexible use of language, picture, analogy and other methods to motivate students to think about the professional issues, inspire students to actively think, read and communication, encourage and organize students to participate in classroom interaction.

\subsection{Diverse Examination.}

At present the assessment of professional English mainly depends on the final exam (accounted for absolute weight). Although this way can play a certain role in strengthening the knowledge, more students focus on mechanical memorization and vocabulary sentence translation. The examination method does not fully examine the ability of flexible use of professional knowledge in listening, speaking, reading and writing. We should establish a scientific evaluation system to encourage students to be more active and enthusiastic in classroom teaching process, let the students realize the importance of speaking, writing ability of professional English.

The reform of the simple assessment method, more flexible and effective way to assess the student performance is necessary to reform the traditional teaching mode. Improve the score of classroom performance, and reduce the proportion of the final exam score, which can increase the students' learning interest in classroom teaching process, and can reflect the students' learning situation and efficiency, so as to promote the improvement of teaching quality through reasonable evaluation system. For example, the final performance of students can be decided by the following sections, that is, the special report, the assessment of small test, reading and writing training, the group research work, according to the students' learning attitude, enthusiasm and learning performance.

\section{Conclusions}

It has become the basic requirements for environmental researchers are able to skillfully use English for academic communication. Therefore, professional English education has become an important part of the current environmental science and engineering professional education. The existing problems in professional English teaching for environmental science and engineering major were analyzed and summarized according to the investigation of the present teaching methods and situations. In order to improve the teaching quality to cultivate students' innovation, writing and 
speaking practice ability, several teaching method were explored and put forward in professional English teaching, such as focusing on selection of suitable textbooks and diverse teaching materials, the innovation of curriculum content, mobilizing the enthusiasm of students through the special report and the special subject study, stimulating students' interest in learning through teaching the latest case or hot issues related with environmental science and engineering, diverse teaching methods and assessment methods, encouraging students to participate in classroom interaction, strengthening the students' speaking and writing training. Through the innovative practice of the above teaching methods, it showed that the teaching quality and performance has been effectively improved so that students' writing ability in English literature and academic communication can be enhanced.

\section{Acknowledgements}

This work was supported by teaching research project foundation of university of Jinan (ZHMXJY1309).

\section{References}

[1] R. N. Susan Bowden MSN. The effect of teaching method on long-term knowledge retention. Journal of Nursing Education.44(2005), 511.

[2] Y.J, Dori, O.Herscovitz. Question-posing capability as an alternative evaluation method: Analysis of an environmental case study. Journal of Research in Science Teaching, 36(1999): 411-430.

[3] H. Xu. Reformation and practice of environmental engineering special English in teaching process, Guangzhou chemical industry, 16(2014), 199-200.

[4]Q. Wang. Application of functional context in translation of environmental English, Overseas English, (2011), 145-147

[5] J.Qian, R.Li, J. Wu, W, Wu. The Exploration and Practice of English Teaching for Environmental

Engineering Majors and Bilingual Instruction Mode.Journal of Hefei University of technology (Social Sciences),23(2009)1-4. 